\title{
Are apathy and depressive symptoms related to vascular white matter hyperintensities in severe late life depression?
}

\author{
Mardien L. Oudega, MSc, MD ${ }^{1,2,5^{*}}$, Amna Siddiqui*, BS ${ }^{1 *}$, Mike P. Wattjes, MD², Frederik \\ Barkhof, MD, $\mathrm{PhD}^{2,4,9}$, Mara ten Kate, $\mathrm{MD}^{4}$, Majon Muller, $\mathrm{MD}, \mathrm{PhD}^{8}$, Filip Bouckaert, $\mathrm{MD}, \mathrm{PhD}^{6}$, \\ Mathieu Vandenbulcke, MD, $\mathrm{PhD}^{6}$, François-Laurent De Winter, MD, Pascal Sienaert, MD, \\ $\mathrm{PhD}^{7}$, Max L. Stek, MD, PhD1, Hannie C. Comijs $\mathrm{PhD}^{1,3}$, Nicole Korten, $\mathrm{PhD}^{1,3}$, Louise Emsell, \\ $\mathrm{PhD}^{6}$, Piet Eikelenboom¹, MD, PhD, Didi Rhebergen, MD, $\mathrm{PhD}^{1,3}$, Eric van Exel, MD, \\ $\mathrm{PhD}^{1,2,3}$, Annemieke Dols, MD, PhD1,2,3
}

${ }^{1}$ GGZ inGeest Specialized Mental Health Care, Amsterdam, The Netherlands

${ }^{2}$ Amsterdam UMC, Vrije Universiteit, Psychiatry, Amsterdam Neuroscience, The Netherlands

${ }^{3}$ Amsterdam UMC, Vrije Universiteit, Psychiatry, Amsterdam Public Health research institute, The Netherlands

${ }^{4}$ Department of Radiology and Nuclear Medicine, Amsterdam UMC, location VUmc, Amsterdam, the Netherlands

${ }^{5}$ Department of Anatomy and Neurosciences, Amsterdam UMC, location VUmc, Amsterdam, the Netherlands

${ }^{6}$ Department of Old Age Psychiatry, University Psychiatric Center KU Leuven (Catholic University of Leuven), Leuven, Belgium

${ }^{7}$ ECT Department, University Psychiatric Center KU Leuven (Catholic University of Leuven), Leuven, Belgium

${ }^{8}$ Department of Internal Medicine, Amsterdam UMC , Amsterdam, the Netherlands

${ }^{9}$ Institute of Neurology and Healthcare Engineering, UCL, London, UK

* Both authors contributed equally to the paper 
Corresponding author: Mardien Leoniek Oudega, m.oudega@ggzingeest.nl, GGZ inGeest Amsterdam UMC, Department of Old Age Psychiatry, Out-patient clinic, Amstelveenseweg 589, 1081 JC Amsterdam, the Netherlands, Tel 0031-6-18479865.

Word count abstract: 250

Word count manuscript: 2322

Tables/figures: 3

Supplements: 0

Acknowledgements:

This study was supported by the Department of Psychiatry of GGZ inGeest and Amsterdam UMC, location VUmc.

FB is supported by the NIHR-ULCH Biomedical Research Centre. 


\section{Abstract}

Objective:

Apathy symptoms are defined as a lack of interest and motivation. Patients with late-life depression (LLD) also suffer from lack of interest and motivation and previous studies have linked apathy to vascular white matter hyperintensities $(\mathrm{WMH})$ of the brain in depressed and non-depressed patients. The aim of this study was to investigate the relationship between apathy symptoms, depressive symptoms and WMH in LLD. We hypothesize that late onset depression (LOD) (first episode of depression after 55 years of age) is associated with WMH and apathy symptoms.

\section{Methods:}

Apathy scores were collected for 87 inpatients diagnosed with LLD. 80 patients underwent brain Magnetic Resonance Imaging (MRI). Associations between depressive and apathy symptoms and WMH were analyzed using linear regression.

Results:

All three subdomains of the 10-item Montgomery-Åsberg Depression Rating Scale correlated significantly with the apathy scale score (all $p<0.05$ ). In the total sample nor apathy or depressive symptoms were related to specific WMH. In LOD only, periventricular WMH were associated with depression severity $(B=5.21, p=0.04)$, while $W M H$ in the left infratentorial region were associated with apathy symptoms ( $B$ coefficient $=5.89, p=0.03$ ). 


\section{Conclusion:}

Apathy and depressive symptoms are highly overlapping in the current cohort of older patients with severe LLD, leading to the hypothesis that apathy symptoms are co-dependent from depressive symptoms in the symptom profile of older patients with severe LLD. Neither apathy nor depressive symptoms could be related to $\mathrm{WMH}$, suggesting that the vascular depression hypothesis is not applicable in severe LLD.

Keywords: apathy symptoms, depression severity, white-matter hyperintensities, late-onset depression, MRI, vascular depression 


\section{Introduction}

Apathy symptoms are reported in many disorders such as Alzheimer's Disease, Parkinson's Disease, stroke, schizophrenia and major depression ${ }^{1}$. Clinically, they are characterized by a lack of interest or diminished self-generated motivation which is not attributable to reduced levels of consciousness or cognitive impairment ${ }^{2}$. Patients diagnosed with major depression also have a lack of interest and diminished motivation ${ }^{3}$, symptoms that are increasingly prominent with age ${ }^{4,5}$. In late-life depression (LLD), apathy symptoms have been correlated with poor response to anti-depressants ${ }^{3,5,6}$, severity of disability ${ }^{7}$, burden on caregivers $^{6}$ and progressive functional decline ${ }^{5}$.

The vascular depression hypothesis suggests that vascular brain lesions lead to depression by disruption of frontal-subcortical-limbic networks involved in mood regulation. Vascular depression may be a subtype of LLD, characterized by combined mood symptoms and executive dysfunction, showing overlap with apathy symptoms ${ }^{8}$. However, despite multiple MRI approaches to shed light on the spatiotemporal structural changes associated with LLD, the causal relationship between vascular brain lesions, and LLD remains controversial ${ }^{9}$.

Previous studies ${ }^{10-13}$ have shown that underlying vascular white matter hyperintensities $(\mathrm{WMH})$ in the aging brain may lead to depression, especially in late-onset depression (LOD), with onset of a first episode above the age of $55-60^{11} 14,15$. Lesions in the basal ganglia damage the connections to the prefrontal area, which are associated with symptoms like lack of insight, lack of energy, and impaired executive functions ${ }^{16}$. These symptoms are part of both depressive and apathy symptomatology. In late life, higher apathy scores and higher depression scores were associated with smaller brain volumes and larger volume of $\mathrm{WMH}^{13}$. 
Previous studies of our group showed that WMH in LLD are associated with high mortality rates after long-term follow-up ${ }^{17 .}$ However, electroconvulsive therapy (ECT) is equally effective in severely depressed patients with and without $\mathrm{WMH}^{18} 19$.

Studies investigating the relationship between apathy symptoms and structural brain damage in patients with LLD are scarce. Due to the overlap between the two, and the incidence of WMH present in LLD, it is important to investigate whether apathy symptoms define a vascular subtype of LLD. The clinical outcome and prognosis of severely depressed older patients may rely on correct characterization of these co-occurring symptoms.

In the current study, we hypothesize that apathy symptoms in severe LLD are associated with $\mathrm{WMH}$ in the cortical-subcortical pathway, specifically in the frontal and basal ganglia regions, in line with the vascular depression hypothesis ${ }^{11}$. The aim of the current study is to evaluate whether WMH on brain magnetic resonance imaging (MRI) are related to depressive symptoms and apathy symptoms in LLD and whether there are differences in patients with early onset depression (EOD), with a first episode of depression before the age of 55, or LOD. Based on previous studies ${ }^{11-12}$ we expect apathy and depressive symptoms to be co-dependent in patients with severe LOD. 


\section{Methods}

\section{Sample}

Patients were recruited for the Mood Disorders in Elderly treated with Electro-Convulsive Therapy (MODECT) study ${ }^{19}$ from two tertiary psychiatric hospitals (GGZ inGeest, Amsterdam, the Netherlands and University Psychiatric Center, KU Leuven, Belgium) after being diagnosed with unipolar severe depression according to the DSM-IV-TR criteria ${ }^{20}$. The patients were aged 55 years or older. Exclusion criteria were a DSM-IV-TR diagnosis of bipolar disorder, schizophrenia and schizoaffective disorder, and neurological illness (Parkinson's Disease, stroke or dementias). The diagnoses were performed by a psychiatrist and confirmed via the Mini International Neuropsychiatric Interview $(\mathrm{MINI})^{21}$ by a research nurse. Collection of data took place from January 2011 till December 2013. A total of 110 patients were included in the total MODECT sample (67 in Amsterdam, 43 in Leuven), out of which 87 were used for analysis in this study. Apathy scores were missing for 23 patients.

\section{Assessments}

Demographic and clinical variables (age, sex, education, site of inclusion, vascular burden, psychotic or not, smoking or not) were assessed by an interview and double-checked via a chart-review. EOD and LOD were defined as a first depressive episode before or after the cutoff age of 55 years. To measure depression severity, the Montgomery Asberg Depression Scale (MADRS) was used ${ }^{22}$. Apathy symptoms in the patients were assessed by means of the 14-item Apathy Scale ${ }^{23}$ with inquiries about interest and apathy on a scale from $0-4$ totaling to a final score of 56 . The 10-item MADRS score was subdivided into negative symptom, depressed mood symptom and somatic symptom scores ${ }^{29,30}$. All three subdomains correlated significantly with the apathy scale score in our sample (negative symptoms, $R=0.38$, depressed mood symptoms, $R=0.42$, somatic symptoms, $R=0.27$, all $p<0.05$ ). The negative symptom items included lack of initiative, reduced emotional reactivity and inattention: these items were 
extracted from the total MADRS score to account for the overlap between apathy symptoms and depression symptoms between the two assessment scales, as previously indicated ${ }^{29,30}$

We also examined the patient's cognitive functioning by the Mini-Mental State Examination $(\mathrm{MMSE})^{24}$. The Dutch version of CORE ${ }^{25,26}$ was employed to grade psychomotor disturbances, with 18 items in 3 subscales on agitation, retardation and non-interactiveness and a total score of 52 .

\section{$M R I$ acquisition and reading}

As previously described ${ }^{17}$, brain MRI was performed on a whole-body 3T MRI system (General Electric Signa HDxt in Amsterdam, Philips Intera in Leuven). Structural 3-dimensional (D) T1weighted,and axial fluid-attenuated inversion recovery (FLAIR) images were acquired. Baseline measurements for the white-matter lesions (WML) were rated on the FLAIR images using the four-point Fazekas scale ${ }^{27}$ and the Age-Related White Matter Changes (ARWMC) scale ${ }^{28}$. The Fazekas scale is a whole brain scale ranging from 0 (no WMH) to 3 (large confluent areas of $\mathrm{WMH}$ ). The ARWMC assesses the $\mathrm{WMH}$ in 10 different brain regions (including the basal ganglia), the score per region ranging from 0 to 3 . The scores of all the regions were used for the analyses and then summed for the total ARWMC score. Periventricular WMH were rated separately on a 3-point scale ranging from 0 (no periventricular $\mathrm{WMH})$ to $2(>5 \mathrm{~mm})$. All the images were reviewed by an experienced neuroradiologist (MW and MtK), who were blinded to all clinical information.

\section{Ethical issues}

The study protocol of MODECT has been approved centrally by the Ethical Review Board of the VU Medical Center and subsequently by the ethical review board of the Catholic University of Leuven and conducted according to the Declaration of Helsinki. Written informed consent was obtained from all the patients. 


\section{Statistics}

Data were analyzed using the Statistical Package of the Social Sciences (SPSS, version 23, SPSS Inc., Chicago, IL). Demographic and clinical characteristics, including MRI visual rating scales, were reported as means with standard deviations, and median and interquartile range for variables with skewed data. Group differences in continuous variables were evaluated using independent t-tests, and a Mann-Whitney test was used if data was not normally distributed after log transformation. In categorical variables, group differences were calculated using $X^{2}$ tests.

Correlation analyses between the apathy scale score and MADRS score subdomains (negative, depressed mood and somatic symptom score) were performed to determine overlap between apathy symptoms and depression severity symptoms, using Pearson's correlation coefficient. The MADRS score subdivision was performed according to Lampe et al. ${ }^{29}$. Linear regression analysis was used to determine associations of WMH (Fazekas, ARWMC, periventricular WML) and the MADRS scores (depression severity) and apathy symptom scores in the total group of patients. The analyses with MADRS scores were adjusted for age and the analyses with apathy scores were adjusted for age and the MADRS score (without the negative symptom items), to correct for depression severity. To study whether the association between $\mathrm{WMH}$ and, respectively, depression and apathy was the same for EOD and LOD we studied the interaction terms. When the interaction term appears to be significant, the analyses will be repeated in both subgroups (EOD and LOD). A p-value of $<0.05$ was considered statistically significant. To correct for multiple testing, a False Discovery Rate (FDR) according to the Benjamini-Hochberg procedure was used based on 13 tests per model. 


\section{Results}

\section{Demographic and clinical characteristics}

The study sample consisted of 87 inpatients diagnosed with severe LLD, who had apathy scores available (Table 1). A total of 61 patients (55.5\%) was diagnosed with LOD. Patients with EOD were significantly younger than patients with LOD (69.3 vs. $72.9, p<0.01)$. Brain MRI characteristics were not significantly different between EOD and LOD, except for the right parieto-occipital ARWMC score (MW=0.03, Table 1). The cohort was homogeneous and no significant differences were observed between the two sites (supplement table 1).

\section{Depression and Apathy symptom score}

The 10-item MADRS score was subdivided into negative symptom, depressed mood symptom and somatic symptom scores ${ }^{29}, 30$. All three subdomains correlated significantly with the apathy scale score in our sample (negative symptoms, $R=0.38$, depressed mood symptoms, $R=0.42$, somatic symptoms, $R=0.27$, all $p<0.05$ ). The negative symptom items included lack of initiative, reduced emotional reactivity and inattention: these items were extracted from the total MADRS score to account for the overlap between apathy symptoms and depression symptoms between the two assessment scales, as previously indicated ${ }^{29,30}$.

\section{Symptoms and White Matter Lesions}

In the total group of patients with LLD, linear regression analysis for the association of WMH with depression severity or and with apathy symptoms did not yield any significant results (Table 2). These $\mathrm{WMH}$ included whole brain $\mathrm{WMH}$ scores, periventricular $\mathrm{WMH}$, total ARWMC scores, and 5 individual brain regions on each hemisphere (frontal, temporal, basal ganglia, infratentorial and parieto-occipital). 
The interaction term between apathy score and onset of depression was significantly associated $(p<0.01)$. In the LOD subgroup, periventricular WMH were associated with depression severity scores ( $p=0.04$; Table 3 ) and ARWMC in the left infratentorial region showed an association with the apathy symptom scores ( $p=0.03$; Table 3 ). In EOD, no significant associations between WMH and depression or apathy scores were found. 


\section{Discussion}

This is the first study evaluating depression severity, apathy symptoms and WMH in severe LLD. Our results show that all three subdomains (negative-, depressed mood- and somatic symptoms) of the 10-item MADRS score correlated significantly with the apathy scale score (all $p<0.05)$. This indicates that apathy symptoms are co-dependent of depressive symptoms in the symptom profile of older patients with severe early and late onset LLD. In the LOD subgroup only, periventricular $\mathrm{WMH}$ are associated with severity of depression, and the presence of WMH in the left infra-tentorial brain region are associated with more apathy symptoms. In the EOD subgroup no associations between $\mathrm{WMH}$ and depression or apathy were found. Thereby we found no indication for a vascular depression hypothesis in severe LLD.

Our findings need to be viewed in regard to previous reports evaluating depressive symptoms, apathy symptoms and WMH. Hollocks et al.. ${ }^{31}$ determined that apathy and depression are both present in patients at risk of small-vessel disease in the brain, and that damage to the corticalsubcortical pathway regulating emotion may be the reason for overlap of symptoms. Hollocks et al. showed also that the two are distinguishable on a neurobiological level and that depression, after controlling for apathy, was not associated with white matter hyperintenisites, but apathy symptoms were associated with WMH. Furthermore, a study by Grool et $a{ }^{13}{ }^{13}$, in a cohort of 4,354 persons without dementia (aged $76 \pm 5$ years) showed that more apathy symptoms, independent of depressive symptoms, were associated with a loss of white-matter volumes and more WMH in the frontal lobe. In contrast with previous literature ${ }^{10,32-34}$, analyses in our cohort of patients with severe LLD did not show any significant associations between $\mathrm{WMH}$ in the frontal and basal ganglia regions, and apathy symptoms or depression severity. Possible explanations for this discrepancy are differences in patient characteristics, most importantly depression severity. In the current cohort, only inpatients with severe depression were included. 
In the cohort of by Grool et al., ${ }^{13}$ and Hollocks et al. patients with mild depressive symptoms were evaluated.

Lampe et al., ${ }^{29}$ evaluated apathy in LLD in relation to age-at-onset, cognitive function or vascular risk. Results showed that apathy is a main feature of moderate to severe LLD and apathy showed to be related to the negative symptoms of the depressive disorder. The authors hypothesize that depression severity may be of more importance in causing the apathy symptoms and it is doubtful whether apathy is a separate syndrome in LLD. This is in line with our current findings and findings in our previous report, showing high ECT response rates in patients with severe LLD, high apathy scores and $\mathrm{WMH}^{19}$.

Current results also show that in the EOD subgroup no associations were observed between $\mathrm{WMH}$ and apathy or depression symptoms. In contrast to what we expected, no significant difference was observed between $\mathrm{WMH}$ in EOD and LOD. This leads to the hypothesis that WML may not be involved in the pathophysiology of severe LOD. Moreover, little differences were found between EOD and LOD in our cohort with severe LLD ${ }^{19}$ indicating that age-at-onset may be an irrelevant specifier in severe depression.

We did find an association between depression severity and periventricular white-matter hyperintensities score in the LOD subgroup $(\mathrm{p}=0.04)$. However, in a meta-analysis by Wang et al., ${ }^{33}$ it was shown that when discriminating between overall, deep and periventricular $\mathrm{WMH}$, only deep WMH were significantly associated with depression. Furthermore, we determined that ARWMC in the left infra-tentorial region are associated with apathy symptoms $(p=0.03)$ in LOD. The disruption of this brain region involves the cerebellum and contributes to coordination, precision and accurate timing: it integrates inputs to fine-tune motor activity. This could imply that $\mathrm{WMH}$ in the cerebellar region are related to apathy symptoms in LOD due to disruption of fine-tune motor activity. But, this result was not observed in previous studies, therefore definite conclusions cannot be drawn. 


\section{Strengths and limitations}

The strength of our study is the design, as it allows for naturalistic recruitment of LLD inpatients admitted to receive ECT for severe depression. The number of recruited patients with severe LLD is higher than those included in previous studies in similar context. Moreover, we were able to evaluate WMH in specific brain areas, which haven't been explored before.

The current study also has limitations. Firstly, the visual rating scales are global indications of the $\mathrm{WMH}$ and depend on the visual inspection of the rater. More precise measurements with quantitative MRI-based methods, such as lesion segmentation or diffusion tensor imaging (DTI) would have improved the study. Secondly, apathy scores of 23 patients were missing because patients refused or were unable to complete the questionnaire with the research nurse. The CORE scores of these 23 patients were significantly higher $(p<0.01)$ and 17 out of 23 patients suffered from a psychotic depression $(p=0.01)$. The patients with missing apathy scores showed less vascular burden ( $p=0.03$ ) but did show higher ARWMC scores in the left and right frontal lobe (respectively, $p=0.02$ and $p=0.03$ ) (supplement table 1). Moreover, psychotic patients of whom apathy scores were obtained showed no significant difference in apathy scores when comparing with non-psychotic patients (24.9 vs. $23.9, p=0.58$ ). This leads to the conclusion that missing data did not influence our results concerning the association between WMH and apathy scores, but missing data could have affected the association between depression severity and WMH in the frontal cortex in patients with depression with psychotic symptoms. Thirdly, analyses of this study were performed cross-sectionally and therefore, no causal relationships can be drawn. However, this specific group referred for and treated with ECT also indicates a strength of this study design, as all patients were severely ill. Moreover, we found that after ECT apathy symptoms may perpetuate in individual patients that were less responsive but this was not associated with $\mathrm{WMH}^{35}$. Thirdly, the risk of inadequate findings due to multiple testing. We addressed this point with correction for multiple testing, according to the Benjamini-Hochberg procedure.

\section{Conclusion}

Apathy and depressive symptoms are highly overlapping in the current cohort of older patients with severe LLD, leading to the hypothesis that apathy symptoms are co-dependent from 
depressive symptoms in the symptom profile of older patients with severe LLD. Neither apathy nor depressive symptoms could be related to $\mathrm{WMH}$, suggesting that the vascular depression hypothesis is not applicable in severe LLD. 


\section{References}

1. Cummings J, Friedman JH, Garibaldi G, Jones M, Macfadden W, Marsh L, Robert PH. Apathy in Neurodegenerative Diseases: Recommendations on the Design of Clinical Trials. $J$ Geriatr Psychiatry Neurol. 2015;28(3):159-73.

2. Marin RS, Firinciogullari S, Biedrzycki RC. The sources of convergence between measures of apathy and depression. J Affect Disord. 1993;28(1):7-14.

3. Alexopoulos GS, Hoptman MJ, Yuen G, Kanellopoulos D, Seirup JK, Lim KO, Gunning FM. Functional connectivity in apathy of late-life depression: a preliminary study. J Affect Disord. 2013;149(1-3):398-405.

4. Krishnan KR, Hays JC, Tupler LA, George LK, Blazer DG. Clinical and phenomenological comparisons of late-onset and early-onset depression. Am J Psychiatry. 1995;152(5):785-8.

5. Groeneweg-Koolhoven I, Comijs HC, Naarding P, de Waal MW, van der Mast RC. Apathy in Older Persons With Depression: Course and Predictors: The NESDO Study. J Geriatr Psychiatry Neurol. 2016;29(4):178-86.

6. Levkovitz Y, Sheer A, Harel EV, Katz LN, Most D, Zangen A, Isserles M. Differential effects of deep TMS of the prefrontal cortex on apathy and depression. Brain Stimul. 2011;4(4):266-74.

7. Yuen GS, Bhutani S, Lucas BJ, Gunning FM, AbdelMalak B, Seirup JK, Klimstra SA, Alexopoulos GS. Apathy in late-life depression: common, persistent, and disabling. Am J Geriatr Psychiatry. 2015;23(5):488-94.

8. Taylor WD, Aizenstein HJ, Alexopoulos GS. The Vascular Depression Hypothesis: Mechanisms Linking Vascular Disease with Depression. Mol Psychiatry. 2013;18(9):963-74.

9. Aizenstein HJ, Baskys A, Boldrini M, Butters MA, Diniz BS, Jaiswal MK, Jellinger KA, Kruglov LS, Meshandin IA, Mijajlovic MD, Niklewski G, Pospos S, Raju K, Richter K, Steffens DC, Taylor WD, Tene O. Vascular depression consensus report - a critical update. BMC Med. 2016 Nov 3;14(1):161.

10. Bae JN, MacFall JR, Krishnan KR, Payne ME, Steffens DC, Taylor WD. Dorsolateral prefrontal cortex and anterior cingulate cortex white matter alterations in late-life depression. Biol Psychiatry. 2006;60(12):1356-63.

11. Lavretsky $\mathrm{H}$, Ballmaier M, Pham D, Toga A, Kumar A. Neuroanatomical characteristics of geriatric apathy and depression: a magnetic resonance imaging study. $A m \mathrm{~J}$ Geriatr Psychiatry. 2007;15(5):386-94.

12. Levy R, Dubois B. Apathy and the functional anatomy of the prefrontal cortex-basal ganglia circuits. Cereb Cortex. 2006;16(7):916-28.

13. Grool AM, Geerlings MI, Sigurdsson S, Eiriksdottir G, Jonsson PV, Garcia ME, Siggeirsdottir K, Harris TB, Sigmundsson T, Gudnason V, Launer LJ. Structural MRI correlates 
of apathy symptoms in older persons without dementia: AGES-Reykjavik Study. Neurology. 2014;82(18):1628-35.

14. Herrmann LL, Le Masurier M, Ebmeier KP. White matter hyperintensities in late life depression: a systematic review. J Neurol Neurosurg Psychiatry. 2008;79(6):619-24.

15. Kirton JW, Resnick SM, Davatzikos C, Kraut MA, Dotson VM. Depressive symptoms, symptom dimensions, and white matter lesion volume in older adults: a longitudinal study. Am $J$ Geriatr Psychiatry. 2014;22(12):1469-77.

16. Alexopoulos GS, Meyers BS, Young RC, Kakuma T, Silbersweig D, Charlson M. Clinically defined vascular depression. Am J Psychiatry. 1997;154(4):562-5.

17.. Oudega ML, van Exel E, Wattjes MP, Comijs HC, Scheltens P, Barkhof F, Eikelenboom P, de Craen AJ, Beekman AT, Stek ML. White matter hyperintensities and cognitive impairment during electroconvulsive therapy in severely depressed elderly patients. Am J Geriatr Psychiatry. 2014 Feb;22(2):157-66. doi:

18. Oudega ML, van Exel E, Wattjes MP, Comijs HC, Scheltens $P$, Barkhof F, Eikelenboom $P$, de Craen AJ, Beekman AT, Stek ML. White matter hyperintensities, medial temporal lobe atrophy, cortical atrophy, and response to electroconvulsive therapy in severely depressed elderly patients. J Clin Psychiatry. 2011 Jan;72(1):104-12

19. Dols A, Bouckaert F, Sienaert P, Rhebergen D, Vansteelandt K, ten Kate M, De Winter F-L, Comijs HC, Emsell L, Oudega ML. Early-and Late-Onset Depression in Late Life: A Prospective Study on Clinical and Structural Brain Characteristics and Response to Electroconvulsive Therapy. Am J Geriatr Psychiatry. 2016.

20. American Psychiatric Association. Diagnostic and Statistical Manual of Mental Disorders, Fourth Edition: DSM-IV-TRß: American Psychiatric Association; 2000.

21. Sheehan DV, Lecrubier Y, Sheehan KH, Amorim P, Janavs J, Weiller E, Hergueta T, Baker R, Dunbar GC. The Mini-International Neuropsychiatric Interview (M.I.N.I.): the development and validation of a structured diagnostic psychiatric interview for DSM-IV and ICD10. J Clin Psychiatry. 1998;59 Suppl 20:22-33;quiz 4-57.

22. Montgomery SA, Asberg M. A new depression scale designed to be sensitive to change. Br J Psychiatry. 1979;134:382-9.

23. Starkstein SE, Mayberg HS, Preziosi TJ, Andrezejewski P, Leiguarda R, Robinson RG. Reliability, validity, and clinical correlates of apathy in Parkinson's disease. $J$ Neuropsychiatry Clin Neurosci. 1992;4(2):134-9.

24. Folstein MF, Folstein SE, McHugh PR. "Mini-mental state". A practical method for grading the cognitive state of patients for the clinician. J Psychiatr Res. 1975;12(3):189-98.

25. Parker G. Defining melancholia: the primacy of psychomotor disturbance. Acta Psychiatr Scand Suppl. 2007;115(433):21-30.

26. Rhebergen D, Arts DL, Comijs H, Beekman AT, Terwee CB, Parker G, Stek ML. Psychometric properties of the dutch version of the core measure of melancholia. $J$ Affect Disord. 2012;142(1-3):343-6. 
27. Fazekas F, Chawluk JB, Alavi A, Hurtig HI, Zimmerman RA. MR signal abnormalities at $1.5 \mathrm{~T}$ in Alzheimer's dementia and normal aging. AJR Am J Roentgenol. 1987;149(2):351-6.

28. Wahlund LO, Barkhof F, Fazekas F, Bronge L, Augustin M, Sjogren M, Wallin A, Ader H, Leys D, Pantoni L, Pasquier F, Erkinjuntti T, Scheltens P. A new rating scale for age-related white matter changes applicable to MRI and CT. Stroke. 2001;32(6):1318-22.

29. Lampe IK, Heeren TJ. Is apathy in late-life depressive illness related to age-at-onset, cognitive function or vascular risk? Int Psychogeriatr. 2004;16(4):481-6.

30. Andersson S, Krogstad JM, Finset A. Apathy and depressed mood in acquired brain damage: relationship to lesion localization and psychophysiological reactivity. Psychol Med. 1999;29(2):447-56.

31. Hollocks MJ, Lawrence AJ, Brookes RL, Barrick TR, Morris RG, Husain M, Markus HS. Differential relationships between apathy and depression with white matter microstructural changes and functional outcomes. Brain. 2015;138(Pt 12):3803-15.

32. Teodorczuk A, O'Brien JT, Firbank MJ, Pantoni L, Poggesi A, Erkinjuntti T, Wallin A, Wahlund LO, Gouw A, Waldemar G, Schmidt R, Ferro JM, Chabriat H, Bazner H, Inzitari D, Group L. White matter changes and late-life depressive symptoms: longitudinal study. $\mathrm{Br} J$ Psychiatry. 2007;191:212-7.

33. Wang L, Leonards CO, Sterzer P, Ebinger M. White matter lesions and depression: a systematic review and meta-analysis. J Psychiatr Res. 2014;56:56-64.

34. Godin O, Dufouil C, Maillard P, Delcroix N, Mazoyer B, Crivello F, Alperovitch A, Tzourio C. White matter lesions as a predictor of depression in the elderly: the 3C-Dijon study. Biol Psychiatry. 2008;63(7):663-9.

35. Carlier A, van Exel E, Dols A, Bouckaert F, Sienaert P, Ten Kate M, Wattjes MP, Vandenbulcke M, Stek ML, Rhebergen D. The course of apathy in late-life depression treated with electroconvulsive therapy; a prospective cohort study. Int J Geriatr Psychiatry. 2018 May 30 . 
Table 1: Sociodemographic, clinical and MRI characteristics

\begin{tabular}{|c|c|c|c|c|}
\hline Sociodemographic & Total $(\mathrm{N}=110)$ & EOD (N=49) & LOD (N=61) & $\begin{array}{l}\text { Statistics comparing EOD and } \\
\text { LOD } X^{2} / t / F / p \text {-value }\end{array}$ \\
\hline $\begin{array}{l}\text { Sex } \\
\text { Female (\%) }\end{array}$ & $73(66.4)$ & $31(63.3)$ & $42(68.9)$ & $X^{2}=0.38(1) \mathrm{p}=0.55$ \\
\hline $\begin{array}{l}\text { Inclusion site } \\
\text { Amsterdam (\%) } \\
\text { Leuven (\%) }\end{array}$ & $\begin{array}{l}67(60.9) \\
43(39.1)\end{array}$ & $\begin{array}{l}32(65.3) \\
17(34.7) \\
\end{array}$ & $\begin{array}{l}35(57.4) \\
26(42.6)\end{array}$ & $X^{2}=0.72(1) p=0.44$ \\
\hline Age of respondent, Mean $( \pm S D)$ & $72.91(8.52)$ & $69.27(7.63)$ & $75.84(8.10)$ & $T=-4.34, F=0.05(108), p<0.01$ \\
\hline \multicolumn{5}{|l|}{ Education } \\
\hline Primary and lower education (\%) & $48(51.1)$ & $16(33.3)$ & $32(66.7)$ & \multirow[t]{3}{*}{$X^{2}=4.19, p=0.12$} \\
\hline Middle secondary education (\%) & $18(19.1)$ & $7(38.9)$ & $11(61.1)$ & \\
\hline Higher secondary education (\%) & $28(29.8)$ & $16(57.1)$ & $12(42.9)$ & \\
\hline \multicolumn{5}{|l|}{ Clinical } \\
\hline $\begin{array}{l}\text { Vascular burden* } \\
\text { Present }(\%)\end{array}$ & $60(54.5)$ & $22(44.9)$ & $28(45.9)$ & $X^{2}=0.01(1) p=1.00$ \\
\hline $\begin{array}{l}\text { Smoking } \\
\text { Never }(\%)\end{array}$ & $\begin{array}{l}\mathrm{N}=94 \\
60(63.8)\end{array}$ & $\begin{array}{l}\mathrm{N}=42 \\
28(66.7)\end{array}$ & $\begin{array}{l}\mathrm{N}=52 \\
32(61.5)\end{array}$ & $X^{2}=0.27(1) p=0.67$ \\
\hline $\begin{array}{l}\text { Clinical diagnosis (MINI) } \\
\text { Psychotic MDD (\%) } \\
\text { Non-psychotic MDD (\%) }\end{array}$ & $\begin{array}{l}56(50.9) \\
54(49.1)\end{array}$ & $\begin{array}{l}28(57.1) \\
21(42.9)\end{array}$ & $\begin{array}{l}26(42.6) \\
35(57.4)\end{array}$ & $X^{2}=2.29(1) p=0.18$ \\
\hline Apathy score, mean $( \pm S D)$ & $\mathrm{N}=87,24.34(7.58)$ & $\mathrm{N}=43,24.00(7.91)$ & $\mathrm{N}=44,24.68(7.32)$ & $\mathrm{T}=-0.42, \mathrm{~F}=1.15(85) \mathrm{p}=0.68$ \\
\hline MADRS score, mean ( \pm SD) & $\mathrm{N}=109,33.55(8.64)$ & $\mathrm{N}=48,32.90(8.84)$ & $\mathrm{N}=58,33.66(8.62)$ & $\mathrm{T}=-0.45, \mathrm{~F}=0.04(104) \mathrm{p}=0.66$ \\
\hline MMSE score, median (IQR) & $\mathrm{N}=97,26.00(6)$ & $\mathrm{N}=44,26.00(5.00)$ & $\mathrm{N}=53,25.00(7.00)$ & MW 0.56 \\
\hline CORE score, median (IQR) & $\mathrm{N}=95,14.00(13.00)$ & $\mathrm{N}=43,13.00(12.00)$ & $\mathrm{N}=52,14.50(13.00)$ & MW 0.36 \\
\hline MRI characteristics & $\mathrm{N}=80$ & $\mathrm{~N}=37$ & $\mathrm{~N}=43$ & \\
\hline Fazekas score, Median (IQR) & $1(1)$ & $1(1)$ & $1(1)$ & MW 0.20 \\
\hline Periventricular WMH score, Median (IQR) & $1(1)$ & $1(1)$ & $1(1)$ & MW 0.34 \\
\hline ARWMC total score, Median (IQR) & $6.5(7)$ & $6.0(6.5)$ & $8.0(7.0)$ & MW 0.43 \\
\hline ARWMC per region scores & $\mathrm{N}=78$ & $\mathrm{~N}=36$ & $\mathrm{~N}=42$ & \\
\hline Left; Frontal & $1(1)$ & $1(0)$ & $1(1)$ & MW 0.50 \\
\hline Left; Parieto-occipital & $1(1)$ & $1(2)$ & $1(1)$ & MW 0.23 \\
\hline Left; Temporal & $0(1)$ & $0(1)$ & $1(1)$ & MW 0.08 \\
\hline Left; Basal ganglia & $0(1)$ & $0(1)$ & $0(1)$ & MW 0.80 \\
\hline Left; Infratentorial & $0(1)$ & $0(1)$ & $0(1)$ & MW 0.65 \\
\hline Right; Frontal & $1(1)$ & $1(0)$ & $1(1)$ & MW 1.00 \\
\hline Right; Parieto-occipital & $1(0)$ & $1(1)$ & $1(1)$ & MW 0.03 \\
\hline Right; Temporal & $0(1)$ & $0(1)$ & $0(1)$ & MW 0.69 \\
\hline Right; Basal ganglia & $0(1)$ & $0(1)$ & $0(1)$ & MW 0.25 \\
\hline Right; Infratentorial & $0(1)$ & $0(1)$ & $0(1)$ & MW 0.59 \\
\hline
\end{tabular}

* presence of hypertension, myocardial infarction, cerebrovascular disease or diabetes mellitus. Statistical tests based on $\mathrm{X}^{2}$ statistics for categorical variables, $\mathrm{t}$-tests for continuous variables, Mann Whitney (MW) for variables without normal distribution, at a significance level of 5\%. EOD: Early-onset depression, LOD: Late-onset depression, SD standard deviation, IQR interquartile range, MINI: 
Mini International Neuropsychiatric Interview, MDD: Major Depressive Disorder, MADRS: Montgomery-Åsberg Depression Rating Scale, MMSE: Mini Mental State Examination, CORE: scale for psychomotor disturbance, WML: White Matter Lesions, ARWMC: Age-Related White Matter Changes 
Table 2: Linear regression results for association of MRI characteristics with MADRS and apathy scores

\begin{tabular}{|c|c|c|c|c|}
\hline \multirow[t]{2}{*}{ Brain MRI characteristics } & \multicolumn{2}{|c|}{$\begin{array}{l}\text { Linear regression model summary for } \\
\text { MADRS* }^{\star}\end{array}$} & \multicolumn{2}{|c|}{$\begin{array}{l}\text { Linear regression model summary } \\
\text { for apathy }{ }^{\star \star}\end{array}$} \\
\hline & Beta-coefficient $(95 \% \mathrm{Cl})$ & p-value & Beta-coefficient (95\% Cl) & p-value \\
\hline Fazekas' score & $2.42(-0.88-5.72)$ & 0.15 & $0.50(-2.12-3.12)$ & 0.70 \\
\hline Periventricular-WMH score & $-3.30(-6.82-0.23)$ & 0.07 & $0.15(-2.57-2.87)$ & 0.91 \\
\hline ARWMC total score & $0.16(-0.31-0.63)$ & 0.50 & $-0.13(-0.49-0.24)$ & 0.50 \\
\hline \multicolumn{5}{|l|}{ ARWMC brain region scores } \\
\hline Left Frontal & $1.11(-2.60-4.83)$ & 0.55 & $-0.74(-3.64-2.17)$ & 0.61 \\
\hline Left Temporal & $0.12(-4.12-4.37)$ & 0.95 & $1.00(-2.39-4.40)$ & 0.56 \\
\hline Left Parieto-occipital & $-0.06(-3.03-2.91)$ & 0.97 & $0.44(-1.86-2.74)$ & 0.70 \\
\hline Left Basal Ganglia & $1.67(-1.06-4.41)$ & 0.23 & $0.14(-1.87-2.14)$ & 0.89 \\
\hline Left Infratentorial & $0.45(-2.52-3.43)$ & 0.76 & $-1.78(-3.96-0.41)$ & 0.11 \\
\hline Right Frontal & $1.64(-1.94-5.22)$ & 0.36 & $-1.04(-3.72-1.63)$ & 0.44 \\
\hline Right Temporal & $0.38(-4.01-4.76)$ & 0.86 & $1.81(-1.50-5.12)$ & 0.28 \\
\hline Right Parieto-occipital & $0.78(-2.25-3.80)$ & 0.61 & $1.80(-0.71-4.32)$ & 0.16 \\
\hline Right Basal Ganglia & $1.07(-1.69-3.82)$ & 0.44 & $-0.61(-2.72-1.50)$ & 0.56 \\
\hline Right Infratentorial & $0.89(-2.23-4.01)$ & 0.57 & $-1.32(-3.56-0.91)$ & 0.24 \\
\hline
\end{tabular}

Number of patients range from 76 to 57 because of missing data for some visual scales. ${ }^{*}$ Linear regression model adjusted for age of respondent ${ }^{* *}$ Linear regression model adjusted for MADRS score without negative symptoms and age of respondent. MADRS: Montgomery Asberg Depression Rating Scale, WML: White matter lesions, ARWMC: Age-related white matter changes. 
Table 3: Linear regression results for association of MRI characteristics with MADRS and apathy scores in LOD

\begin{tabular}{|c|c|c|c|c|}
\hline \multirow{2}{*}{ MRI characteristics } & \multicolumn{2}{|l|}{ LOD and MADRS* } & \multicolumn{2}{|l|}{ LOD and apathy ${ }^{\star \star}$} \\
\hline & Beta-coefficient $(95 \% \mathrm{Cl})$ & p-value & Beta-coefficient $(95 \% \mathrm{Cl})$ & p-value \\
\hline Fazekas' score & $1.57(-3.81-6.94)$ & 0.56 & $-1.40(-6.72-3.93)$ & 0.59 \\
\hline Periventricular WML & $-5.21(-10.16-(-0.25))$ & $0.04^{*}$ & $-2.18(-6.85-2.50)$ & 0.35 \\
\hline ARWMC total score & $-0.13(-0.80-0.55)$ & 0.71 & $-0.47(-1.09-0.15)$ & 0.13 \\
\hline \multicolumn{5}{|l|}{ ARWMC brain region scores } \\
\hline Left frontal & $-1.72(-7.10-3.66)$ & 0.52 & $-3.76(-8.42-0.90)$ & 0.11 \\
\hline Left parieto-occipital & $-2.06(-6.65-2.54)$ & 0.37 & $0.23(-4.26-4.72)$ & 0.92 \\
\hline Left basal ganglia & $0.88(-3.60-5.36)$ & 0.69 & $-1.16(-5.77-3.45)$ & 0.61 \\
\hline Left temporal & $-1.80(-7.53-3.94)$ & 0.53 & $-3.63(-9.15-1.90)$ & 0.19 \\
\hline Left infratentorial & $1.11(-5.29-7.51)$ & 0.73 & $-5.89(-11.26-(-0.51))$ & $0.03^{*}$ \\
\hline Right frontal & $-1.11(-6.47-4.26)$ & 0.68 & $-3.54(-7.93-0.86)$ & 0.11 \\
\hline Right parieto-occipital & $-0.53(-4.65-3.59)$ & 0.80 & $0.64(-3.43-4.70)$ & 0.75 \\
\hline Right basal ganglia & $-0.13(-3.96-3.70)$ & 0.95 & $-1.58(-5.11-1.94)$ & 0.36 \\
\hline Right temporal & $-1.22(-7.21-4.78)$ & 0.68 & $3.61(-1.33-8.55)$ & 0.15 \\
\hline Right infratentorial & $1.46(-4.22-7.15)$ & 0.61 & $-3.57(-8.48-1.35)$ & 0.15 \\
\hline
\end{tabular}

*Linear regression model adjusted for age of respondent ${ }^{* *}$ Linear regression model adjusted for MADRS score without negative symptoms and age of respondent. LOD: Late-onset depression, MADRS: Montgomery Asberg Depression Rating Scale, WML: White matter lesions, ARWMC: Age-related white matter changes. * Significant after correction for multiple testing using the False Discovery Rate Benjamini-Hochberg procedure based on 13 tests per model. 